\title{
Array-based molecular karyotyping in fetuses with isolated brain malformations identifies disease-causing CNVs
}

\author{
Madita Schumann ${ }^{1}$, Andrea Hofmann 1,2, Sophia K. Krutzke', Alina C. Hilger ${ }^{1}$, Florian Marsch', Dietlinde Stienen ${ }^{1}$, \\ Ulrich Gembruch ${ }^{3}$, Michael Ludwig ${ }^{4}$, Waltraut M. Merz ${ }^{3}$ and Heiko Reutter ${ }^{1,5^{*}}$
}

\begin{abstract}
Background: The overall birth prevalence for congenital malformations of the central nervous system (CNS) among Europeans may be as high as 1 in 100 live births. The etiological factors remain largely unknown. The aim of this study was to detect causative copy number variations (CNVs) in fetuses of terminated pregnancies with prenatally detected isolated brain malformations.

Methods: Array-based molecular karyotyping was performed in a cohort of 35 terminated fetuses with isolated CNS malformations. Identified putative disease-causing CNVs were confirmed using quantitative polymerase chain reaction or multiplex ligation-dependent probe amplification.

Results: Based on their de novo occurrence and/or their established association with congenital brain malformations, we detected five disease-causing CNVs in four fetuses involving chromosomal regions 6p25.1-6p25.3 (FOXC1), 6q27, 16p12.3, Xp22.2-Xp22.32 (MID1), and Xp22.32-Xp22.33. Furthermore, we detected a probably disease-causing CNV involving chromosomal region 3p26.3 in one fetus, and in addition, we detected 12 CNVs in nine fetuses of unknown clinical significance. All CNVs except for two were absent in 1307 healthy in-house controls (frequency <0.0008). Each of the two CNVs present in in-house controls was present only once (frequency $=0.0008$ ). Furthermore, our data suggests the involvement of CNTN6 and KLHL15 in the etiology of agenesis of the corpus callosum, the involvement of RASD1 and PTPRD in Dandy-Walker malformation, and the involvement of ERMARD in ventriculomegaly.
\end{abstract}

Conclusions: Our study suggests that CNVs play an important role in the etiology of isolated brain malformations.

Keywords: Array-based karyotyping, Brain malformation, Copy number variation (CNV), De novo occurrence

\section{Background}

Congenital malformations of the brain can either be isolated or non-isolated and can affect both the neural tube and/or the brain. The overall birth prevalence among Europeans may be as high as 1 in 100 live births [1, 2]. Malformations of the brain represent a broad clinical spectrum, ranging from thinning of the corpus callosum to isolated partial or complete agenesis of corpus callosum or to alobar holoprosencephaly with complete absence of the corpus callosum [3]. These malformations

\footnotetext{
* Correspondence: reutter@uni-bonn.de

${ }^{1}$ Institute of Human Genetics, University of Bonn, Bonn, Germany

${ }^{5}$ Department of Neonatology and Pediatric Intensive Care \& Institute of Human Genetics, University of Bonn, Sigmund-Freud-Str. 25, D-53127 Bonn, Germany

Full list of author information is available at the end of the article
}

may present in isolation, in association with other anomalies or as part of complex genetic syndromes. Prenatal imaging by ultrasound and magnetic resonance imaging (MRI) nowadays allows detection of most of these malformations. Based on the assumption of an impaired neurocognitive outcome, prenatal diagnosis often leads to termination of pregnancy (ToP) [4]. The underlying causes are extremely heterogeneous. Among the periconceptional or pregnancy-associated environmental risk factors are maternal intake of medications (e.g., valproate), embryonic or fetal infections (viral or parasitic, e.g., rubella, cytomegaly, or toxoplasma gondii), or maternal folic acid deficiency [5]. Among the known genetic factors are chromosomal abnormalities (e.g., trisomy 13, 18, Miller-Dieker lissencephaly syndrome [MIM \#247200]) or 
monogenic syndromes (e.g., Joubert syndrome or holoprosencephaly type 3) [6]. However, for the majority of brain malformations, the underlying cause remains unknown.

Recent reports on the systematic investigation of underlying copy number variations (CNVs) suggest diseasecausing CNVs (losses or gains of haploinsufficient or triplosensitive genomic material), to play an important role in the etiology [7-11]. In this respect, our own group recently investigated a larger cohort of fetuses from terminated pregnancies with prenatally detected syndromic brain malformations (brain malformations and additional extra-cerebral anomalies) [12]. In that cohort, we detected seven disease-causing $\mathrm{CNVs}$ and four probably diseasecausing CNVs that were not present in our 1307 healthy in-house controls (frequency $<0.0008$ ).

Here, we report screening of 35 terminated fetuses with prenatally detected isolated brain malformations, using an array-based genome-wide approach to search for causative CNVs.

\section{Methods}

\section{Subjects and DNA isolation}

This study was approved by the local ethics committee, and all women provided written informed consent. The primary fetal study cohort was sampled between 2006 and 2012 through the Department of Obstetrics and Prenatal Medicine at the University of Bonn. During this time, fetal blood samples of over 400 fetuses were collected in the context of fetocide. In all cases, ToP was carried out in accordance with the German legislation. Among these fetuses, 35 presented with isolated brain malformations. Fetuses with additional extra-cerebral anomalies such as heart defects, renal anomalies, or skeletal dysplasia were excluded from the analyses. Also, fetuses with numeric chromosomal aberrations or prenatally detected monogenic syndromes were excluded.

In two of 35 fetuses, DNA quality was insufficient for array-based molecular karyotyping. Saliva samples from parents were obtained after discharge from hospital. For 10 of the 33 fetuses with sufficient DNA quality, both parents participated. Isolation of genomic DNA was carried out using either the QIAmp DNA Blood Kit (Qiagen, Hilden, Germany) or Chemagic Magnetic Separation Module I (Chemagen, Baesweiler, Germany). In the case of saliva samples, the Oragene DNA Kit (DNA Genotek Inc, Ontario, Canada) was used. For candidate gene deletion screening, we analyzed 19 additional fetuses with syndromic non-isolated Dandy-Walker malformation related brain anomalies of whom no array-based molecular karyotyping had been previously performed and which had also been sampled through the Department of Obstetrics and Prenatal Medicine at the University of Bonn.

\section{Prenatal conventional karyotyping}

Of the 35 fetuses, 33 had sufficient DNA quality for array-based analysis. Of these 33 fetuses, only prenatal conventional karyotyping had been performed in 28 fetuses, one had FISH analysis only. In one fetus prenatal, conventional karyotyping and CGH array were performed. Here, a microscopically visible structural chromosomal aberration had been detected showing deletion of chromosomal region Xp22.32p22.2 (fetus 14; see Table 1). Conventional prenatal karyotyping of the remaining 28 fetuses and the FISH analysis in one fetus gave normal results. The two fetuses with insufficient DNA quality for array-based molecular karyotyping had also prenatal conventional karyotyping showing normal results.

\section{Array-based molecular karyotyping}

For array-based molecular karyotyping, we used the Illumina HumanOmniExpress-12 v1.0 BeadChip (marker content 730,525; median marker spacing $2.1 \mathrm{~kb}$; Illumina. Inc., San Diego, CA). All analyses were performed according to the manufacturer's protocol. A DNA sample was considered to have failed if $<95 \%$ of the SNP markers were called on the corresponding BeadChip. CNVs were predicted using the program QuantiSNP (v2.2, www.well.ox.ac.uk/QuantiSNP/) which applies an Objective-Bayes Hidden-Markov model [13].

\section{CNV filtering}

Initial filtering of $\mathrm{CNV}$ data was carried out using the following seven criteria to exclude CNVs: (I) QuantiSNP quality measurement with a "log Bayes factor" <30; (II) regions with less than three aberrant markers; and (III) frequency of $>1 \%$ in our in-house control cohort ( $n=1307$ healthy controls). A series of manual filter steps was then applied: In manual step (IV), all remaining CNVs were checked visually in GenomeStudio v2011.2 (Illumina, San Diego, CA). (V) All remaining CNVs were filtered for RefSeq gene content (coding regions only, http://www.ncbi.nlm.nih.gov/refseq/rsg/) using the UCSC genome browser assembly hg19 (http://genome.ucsc.edu). $\mathrm{CNVs}$ that did not harbor central nervous system (CNS)associated or CNS-expressed genes listed in Mouse Genome Informatics (MGI) or Expert Protein Analysis System (ExPASy) were excluded. In manual step (VI), CNVs were filtered according to their presence in healthy control persons in the publicly available database of Genomic Variants (DGV, http://dgvbeta.tcag.ca/dgv/app/home?ref=NCBI36/hg19). CNVs with at least five fully overlapping reports in DGV were excluded. In manual step (VII), the remaining $\mathrm{CNVs}$ were re-evaluated visually using the GenomeStudio genotyping module (v2011.2, http:// www.illumina.com/) to check whether the breakpoints had been called correctly by QuantiSNP. If another brain- 
Table 1 Fetal phenotype and genetic findings

\begin{tabular}{|c|c|c|c|c|c|c|c|c|c|c|}
\hline \multirow{2}{*}{$\begin{array}{l}\text { Fetus genetic } \\
\text { findings }\end{array}$} & \multicolumn{2}{|l|}{ Fetus 14} & Fetus 1 & \multicolumn{2}{|l|}{ Fetus 2} & \multirow{2}{*}{$\begin{array}{l}\text { Fetus } 3 \\
\text { Male }\end{array}$} & \multirow{2}{*}{$\begin{array}{l}\text { Fetus } 4 \\
\text { Male }\end{array}$} & Fetus 5 & \multicolumn{2}{|l|}{ Fetus 6} \\
\hline & Female & & Male & Female & & & & Male & Female & \\
\hline $\begin{array}{l}\text { Rearrangement } \\
\text { (size in } \mathrm{Mb} \text { ) }\end{array}$ & $\begin{array}{l}\text { delXp22.2- } \\
\text { Xp23.2 } \\
(7.2)\end{array}$ & $\begin{array}{l}\text { dupXp22.33- } \\
\text { Xp22.32 } \\
(1.93)\end{array}$ & del6q27 (0.78) & $\begin{array}{l}\text { dup2q32.1- } \\
2 q 32.2 \\
(0.39)\end{array}$ & $\begin{array}{l}\text { del16q12.11 } \\
(0.10)\end{array}$ & dup3q26.1 (0.51) & del3p26.3 (0.07) & $\begin{array}{l}\text { del } 4 q 31.23 \\
(0.18)\end{array}$ & $\begin{array}{l}\text { dup4q13.3 } \\
(0.25)\end{array}$ & $\begin{array}{l}\text { dup8q24.3 } \\
(0.09)\end{array}$ \\
\hline De novo & Yes & Yes & Yes & n.t. & n.t. & n.t. & n.t. & n.t. & n.t. & n.t. \\
\hline \multirow{2}{*}{$\begin{array}{l}\text { 1st and last } \\
\text { Mutated SNP }\end{array}$} & rs5915786 & rs5916528 & rs9383520 & rs74244417 & rs4967746 & rs4680608 & rs9840732 & rs17023845 & rs1381015 & rs7819263 \\
\hline & rs5978478 & rs7881910 & rs12530134 & rs997277 & rs16952589 & rs2863381 & rs9856251 & rs13129809 & rs10028486 & rs10112201 \\
\hline \multirow[t]{2}{*}{ Flanking SNPs } & rs6530416 & Telomer & rs9478086 & rs7574262 & rs12930613 & rs1355538 & rs3843386 & rs6845560 & rs11941162 & rs3824233 \\
\hline & rs1526798 & rs7391672 & Telomer & rs1516445 & rs11863453 & rs10936492 & rs172171 & rs10025443 & rs714825 & rs6578185 \\
\hline $\begin{array}{l}\text { RefSeq genes } \\
\text { affected }\end{array}$ & 23 & 10 & 13 & 2 & 1 & 1 & 1 & 1 & 2 & 2 \\
\hline $\begin{array}{l}\text { Phenotypic } \\
\text { findings }\end{array}$ & \multicolumn{2}{|c|}{ Callosal agenesis } & $\begin{array}{l}\text { Isolated } \\
\text { symmetric } \\
\text { internal } \\
\text { hydrocephalus }\end{array}$ & \multicolumn{2}{|c|}{$\begin{array}{l}\text { Isolated symmetric } \\
\text { internal hydrocephalus }\end{array}$} & $\begin{array}{l}\text { ACC, colpocephaly } \\
\text { and missing septum } \\
\text { pellucidi }\end{array}$ & $\begin{array}{l}\text { ACC, hydrocephalus, hypoplastic } \\
\text { cerebellum, suspected lissencephaly }\end{array}$ & $\begin{array}{l}\text { Macrocephaly, } \\
\text { internal } \\
\text { hydrocephalus }\end{array}$ & \multicolumn{2}{|c|}{$\begin{array}{l}\text { Alobar } \\
\text { holoprosencephaly }\end{array}$} \\
\hline $\begin{array}{l}\text { Prenatal } \\
\text { karyotyping }\end{array}$ & \multicolumn{2}{|c|}{$\begin{array}{l}\text { Yes, microdeletion } \\
\text { Xp22.2-p23.2 }\end{array}$} & $\begin{array}{l}\text { Yes, no results } \\
\text { available }\end{array}$ & \multicolumn{2}{|l|}{ Yes, normal } & Yes, normal & Yes, normal & Yes, normal & \multicolumn{2}{|l|}{ Yes, normal } \\
\hline \multirow{2}{*}{$\begin{array}{l}\text { Fetus genetic } \\
\text { findings }\end{array}$} & \multicolumn{2}{|l|}{ Fetus 7} & Fetus 8 & \multicolumn{2}{|l|}{ Fetus 9} & Fetus 10 & Fetus 11 & Fetus 12 & \multicolumn{2}{|l|}{ Fetus 13} \\
\hline & \multicolumn{2}{|l|}{ Female } & Male & \multicolumn{2}{|l|}{ Male } & Female & Female & Male & \multicolumn{2}{|l|}{ Male } \\
\hline $\begin{array}{l}\text { Rearrangement } \\
\text { (size in Mb) }\end{array}$ & \multicolumn{2}{|c|}{ dup9p23 (1.25) } & del18p11.21 (0.19) & $\begin{array}{l}\text { dup2q37.3 } \\
(0.10)\end{array}$ & $\begin{array}{l}\text { dup3q13.32 } \\
(0.08)\end{array}$ & $\begin{array}{l}\text { dup17p11.2-17p12 } \\
(2,43)\end{array}$ & del16p12.2 (0.57) & $\begin{array}{l}\text { del6p25.1- } \\
6 p 25.3(4,65)\end{array}$ & \multicolumn{2}{|c|}{ dupXp22.11 (0.21) } \\
\hline De novo & \multicolumn{2}{|l|}{ n.t. } & n.t. & n.t. & n.t. & n.t. & No paternal inheritance & Yes & \multicolumn{2}{|l|}{ Maternal } \\
\hline \multirow{2}{*}{$\begin{array}{l}\text { 1st and last } \\
\text { mutated SNP }\end{array}$} & \multicolumn{2}{|l|}{ rs12552479 } & rs522631 & rs4676385 & rs4687836 & rs4792576 & rs670841 & rs6930285 & \multicolumn{2}{|l|}{ rs5925934 } \\
\hline & \multicolumn{2}{|l|}{ rs1335475 } & rs1592643 & rs2288750 & rs2917080 & rs4646341 & rs8062140 & rs808601 & \multicolumn{2}{|l|}{ rs10521917 } \\
\hline \multirow[t]{2}{*}{ Flanking SNPs } & \multicolumn{2}{|l|}{ rs1441400 } & rs496485 & rs2975778 & rs9878706 & rs9907064 & rs8054407 & Telomer & rs7879340 & \\
\hline & rs7038987 & & rs9960249 & rs4234121 & rs2903301 & rs12449964 & rs9928431 & rs3804547 & rs6526366 & \\
\hline $\begin{array}{l}\text { RefSeq genes } \\
\text { affected }\end{array}$ & 2 & & 1 & 2 & 1 & 42 & 7 & 35 & 4 & \\
\hline $\begin{array}{l}\text { Phenotypic } \\
\text { findings }\end{array}$ & $\begin{array}{l}\text { DWM, micrc } \\
\text { hydrocepha }\end{array}$ & $\begin{array}{l}\text { ocephaly, } \\
\text { alus }\end{array}$ & $\begin{array}{l}\text { Occlusive } \\
\text { hydrocephalus }\end{array}$ & Internal hyd & rocephalus & DWM & $\begin{array}{l}\text { ACC, asymmetry of the ventricles, } \\
\text { hypoplastic cerebellum, } \\
\text { interhemispheric cysts, median shift }\end{array}$ & DWM & ACC & \\
\hline $\begin{array}{l}\text { Prenatal } \\
\text { karyotyping }\end{array}$ & Yes, normal & & No & Yes, no resu & Its available & $\begin{array}{l}\text { Only FISH analysis, } \\
\text { normal }\end{array}$ & Yes, normal & Yes, normal & Yes, normal & \\
\hline
\end{tabular}

ACC agenesis of the corpus callosum, DWM Dandy-Walker malformation, FISH fluorescence in situ hybridization, n.t. not tested 
related gene may have been affected, we included the flanking region in the quantitative polymerase chain reaction (qPCR) validation. All data are designated according to hg19.

\section{Validation with quantitative polymerase chain reaction}

The qPCR analyses were performed to confirm all putative fetal CNVs and for parental segregation analyses to detect de novo events. Reactions were performed on an ABI Prism 7900HT Fast Real-Time PCR System with SYBR Green (Applied Biosystems, Foster City, CA), using three to four primer pairs per putative $\mathrm{CNV}$ as described elsewhere [14]. Primer sequences are obtainable on request.

\section{Multiplex ligation-dependent probe amplification for CNV confirmation and cohort screening}

For CNV confirmation of the FOXC1 containing CNV, multiplex ligation-dependent probe amplification (MLPA) analysis was performed using the SALSA MLPA probemix P208-C1 Human Telomere-6 (MRC-Holland, Amsterdam, Netherlands). For cohort screening of additional fetuses, we used SALSA MLPA P054 FOXL2-TWIST1 probemix containing probes for FOXC1 (MRC-Holland, Amsterdam, Netherlands).

\section{Results}

For 33 fetal samples, the array quality was sufficient for analysis. In these samples, QuantiSNP called 4569 putative CNVs. After the application of filter criteria I-IV, 48 $\mathrm{CNVs}$ remained. The application of filter criteria V-VI decreased this number to 18 , comprising ten duplications and eight deletions in a total of 14 fetuses (Table 1). Sizes ranged from 0.07 to $9.23 \mathrm{Mb}$. Ten fetuses carried a single change, and four fetuses carried two (both duplication and deletion). Seventeen of the $18 \mathrm{CNVs}$ were submicroscopic, and one had already been identified with prenatal conventional karyotyping (see above; fetus 14). Sixteen of the 17 submicroscopic CNVs identified in fetuses were confirmed using quantitative PCR (qPCR) and one using multiplex ligation-dependent probe amplification. In three fetuses (fetuses 1, 12, and 14) the de novo origin of four CNVs could be confirmed. In a further fetus (fetus 11), paternal inheritance could be excluded; however, maternal DNA quality was insufficient and further sampling was declined. In another male fetus (fetus 13), maternal inheritance of a dupXp22.11 was confirmed. In the remaining 10 fetuses, CNVs could not be investigated for inheritance, as no parental DNA was available. Sixteen of the identified changes were absent in any of our 1307 healthy in-house controls (frequency $<0.0008$ ); two of the identified changes, both in fetus 9 , were each present once in our 1307 healthy in-house controls (frequency $=0.0008$ ).
Fetuses without prenatal conventional karyotyping

Fetus 1 (GA [gestational age, in completed weeks plus days] $25+2$ ) was diagnosed by prenatal ultrasound with symmetric bilateral ventriculomegaly. The fetus carried a $0.78-\mathrm{Mb}$ deletion of chromosomal region 6q27 (Chr6:170,140,184-170,919,470) comprising 13 RefSeq genes. qPCR analyses in fetus and the parents showed a de novo occurrence of the deletion in the fetus. Overlapping deletions have been previously observed in patients with brain anomalies [15].

Fetus 8 (GA $24+3$ ) was diagnosed by prenatal ultrasound with ventriculomegaly of all four ventricles and secondary macrocephaly. The fetus carried a $0.19-\mathrm{Mb}$ deletion of chromosomal region 18p11.21 (chr18:12,456,559$12,643,193)$ comprising most of the spire-type actin nucleation factor 1 gene (SPIRE1, MIM 609216).

Fetus 10 (GA $22+6)$ was diagnosed by prenatal ultrasound with Dandy-Walker variant (hypoplasia of the vermis cerebelli). The fetus carried a $2.43-\mathrm{Mb}$ duplication of chromosomal region 17p11.2-17p12 (chr17:15,063,83217,493,810) involving 42 RefSeq genes. The proximal part of this duplication has been associated with PotockiLupski syndrome [16], resulting from variable duplications at $17 \mathrm{p} 11.2$.

\section{Fetuses with prenatal conventional karyotyping}

Fetus 2 (GA $25+6)$ was diagnosed by prenatal ultrasound with isolated, symmetric bilateral ventriculomegaly. The fetus carried a $0.39-\mathrm{Mb}$ duplication of chromosomal region 2q32.1-2q32.2 (chr2:189,363,100$189,750,863)$ comprising the complete coding regions of the two RefSeq genes GULP1 (PTB domain containing engulfment adaptor protein 1, MIM 608165) and DIRC1 (mRNA disrupted in renal carcinoma 1, MIM 606423). This fetus carried an additional $0.1-\mathrm{Mb}$ deletion of chromosomal region 16q12.11 (chr16:47,074,235$47,174,275)$ comprising exons $2-9$ of the NETO2 gene (neuropilin and tolloid (TLL)-like 2, MIM 607974).

Fetus 3 (GA $12+6)$ was diagnosed by prenatal ultrasound with agenesis of the corpus callosum (ACC) (colpocephaly and absent septum pellucidum). The fetus carried a $0.51-\mathrm{Mb}$ duplication of chromosomal region 3q26.1 (chr3:165,553,646-166,065,099) affecting BCHE gene exon 1 (butyrylcholinesterase, MIM 177400).

Fetus 4 (GA 24+0) was diagnosed by prenatal ultrasound with symmetric bilateral ventriculomegaly, cerebellar hypoplasia, ACC, and signs of lissencephaly. The fetus carried a $0.07-\mathrm{Mb}$ deletion of chromosomal region 3p26.3 (chr3:1,436,664-1,511,108), comprising the last three exons (21-23) of the CNTN6 gene (contactin 6, MIM 607220). CNVs comprising CNTN6 have recently been associated with neurodevelopmental discorders and brain anomalies $[17,18]$. 
Fetus 5 (GA $21+3)$ was diagnosed by prenatal ultrasound with occlusive hydrocephalus (with dilatation of the lateral and third ventricles, suggesting aquaeductal stenosis) and secondary macrocephaly. The fetus carried a $0.18-\mathrm{Mb}$ deletion of chromosomal region $4 \mathrm{q} 31.23$ (chr4:148,727,355-148,903,388), comprising the single RefSeq gene ARHGAP10 (Rho GTPase activating protein 10, MIM 609746).

Fetus $6($ GA $23+4)$ was diagnosed by prenatal ultrasound with alobar holoprosencephaly. The fetus carried two duplications. The first duplication was $0.25 \mathrm{Mb}$ in size affecting chromosomal region 4q13.3 (chr4:73,812,806$74,058,406)$ comprising the complete coding region of the COX18 gene (cytochrome c oxidase assembly factor, MIM 610428) and part of the ANKRD17 gene (ankyrin repeat domain 17, MIM 615929). The second duplication was $0.09 \mathrm{Mb}$ in size affecting chromosomal region 8q24.3 (chr8:142,295,965-142,382,757). The region comprises the complete GPR20 gene (G protein-coupled receptor 20, MIM 601908) and the long non-coding RNA LOC7311779.

Fetus 7 (GA $27+5)$ was diagnosed by prenatal ultrasound with Dandy-Walker malformation (agenesis of the vermis cerebelli) with bilateral symmetric ventriculomegaly and microcephaly. The fetus carried a $1.25-\mathrm{Mb}$ duplication of chromosomal region 9p23 (chr9:10,144,584$11,398,305)$ affecting the PTPRD gene (protein-tyrosine phosphatase, receptor-type, delta, MIM 601598) and its complete long non-coding RNA, antisense RNA 2 (head to head) (PTPRD-AS2).

Fetus 9 (GA $21+6)$ was diagnosed by prenatal ultrasound with symmetric bilateral ventriculomegaly and secondary macrocephaly. This fetus carried two duplications. The first duplication was $0.1 \mathrm{Mb}$ in size affecting chromosomal region 2q37.3 (chr2:241,623,894$241,722,445)$ comprising the two RefSeq genes KIF1A (kinesin family member 1A, MIM 601255) and $A Q P 12 A$ (aquaporin 12A, MIM 609789). Here, the $K I F 1 A$ gene has been associated with hereditary sensory and autonomic neuropathy type II and in autosomal recessive spastic paraparesis as well as spastic paraplegia [19-21]. The second duplication was $0.08 \mathrm{Mb}$ in size affecting chromosomal region 3q13.32 (chr3:118,730,933-118,812,027) comprising intron 3 of the IGSF11 gene (immunoglobulin superfamily, member 11, MIM 608351).

Fetus 11 (GA $28+3$ ) was diagnosed by prenatal ultrasound with ACC (colpocephaly and absent septum pellucidum) and interhemispheric arachnoidal cysts. This fetus carried a $0.57-\mathrm{Mb}$ deletion of chromosomal region 16p12.2 (chr16:21,839,340-22,409,463). This region comprises seven RefSeq genes namely UQCRC2 (ubiquinolcytochrome c reductase core protein II, MIM 191329), PDZD9 (PDZ domain containing 9), C16orf52, VWA3A (von Willebrand factor A domain containing $3 \mathrm{~A}$ ), EEF2K (eukaryotic elongation factor 2 kinase, MIM 606968), POLR3E (polymerase (RNA) III (DNA directed) polypeptide $\mathrm{E}(80 \mathrm{kD}))$, and $C D R 2$ (cerebellar degenerationrelated protein 2, MIM 117340).

Fetus 12 (GA $22+3)$ was diagnosed by prenatal ultrasound with Dandy-Walker malformation (agenesis of the vermis cerebelli with bilateral, symmetric ventriculomegaly and secondary macrocephaly). The fetus carried a 4.65-Mb deletion of chromosomal region 6p25.1-6p25.3 (chr6:212,548-4,864,581) comprising 35 RefSeq genes. $\mathrm{CNV}$ validation via MLPA confirmed the deletion and analysis of parental DNA established its de novo occurrence. Among the deleted genes resides FOXC1 (forkhead box C1, MIM 601090). Point mutations and deletions of FOXC1 have been shown to play a major role in the formation of Dandy-Walker malformations $[22,23]$.

Prompted by our finding of a deletion in fetus 12 comprising FOXC1, we used a region-specific high-density MLPA probe (see above) to screen 19 additional fetuses with syndromic non-isolated Dandy-Walker malformationrelated brain anomalies of whom no array-based molecular karyotyping had been previously performed. However, this additional analysis failed to detect any further deletions (or duplications) of the FOXC1 region.

Fetus 13 (GA $23+4$ ) was diagnosed by prenatal ultrasound with ACC. The fetus carried a $0.21-\mathrm{Mb}$ duplication of chromosomal region Xp22.11 (chrX:23,799,47224,012,381). The region comprises four RefSeq genes encoding SAT1 (spermidine/spermine N1-acetyltransferase, MIM 313020), APOO (apolipoprotein O, MIM 300753), CXOrf58, and KLHL15 (kelch-like family member 15). Interestingly, KLHL15 was most recently identified as a potential $\mathrm{X}$-linked intellectual disability (ID) gene [24]. Investigation of parental DNA showed transmittance of this CNV from the healthy mother.

Fetus $14($ GA $28+5)$ was diagnosed by prenatal ultrasound with ACC. The female fetus carried a 7.2-Mb deletion of chromosomal region Xp22.2-Xp22.32 (chrX:4,642,016-11,935,042) comprising 23 RefSeq genes. Among these genes is the midline 1 (MID1) gene. Mutations in MID1 have been associated with the X-linked form of Opitz syndrome [25], which is characterized by midline abnormalities such as cleft lip, laryngeal cleft, heart defects, hypospadias, and ACC [26]. Furthermore, and on the same Xchromosome, the fetus carried a 1.93-Mb duplication, involving chromosomal region Xp22.32-Xp22.33 (chrX:2,700,157-4,628,697), comprising the following 12 RefSeq genes: GYG2 (glycogenin 2, MIM 300198), $X G$ (Xg blood group, MIM 300879), ARSD (arylsulfatase D, MIM 300002), ARSE, ARSH, ARSF (arylsulfatases E, H, and F, MIM 300180, 300586, 300003), MXRA5 (matrix-remodeling associated 5, MIM 
300938), PRKX (protein kinase, X-linked, MIM 300083) and its long non-coding RNA (PRKX-AS1), long intergenic non-protein coding RNA 1546 (LINC01546), and the uncharacterized long noncoding RNAs LOC101928201 and LOC389906. qPCR $\mathrm{CNV}$ validation and segregation analysis of the fetus and the parents confirmed both the deletion and the duplication and revealed their de novo occurrence in the fetus.

\section{Discussion}

During embryonic and fetal life, the CNS forms and later matures in a complex developmental process. Milestones in early gestation are pattern formation (induction of the neurectoderm and segmentation of the neural tube) and morphogenetic events like neurulation, resulting in the folding of the neural tube and prosencephalon. Starting in mid-gestation, neuronal proliferation, migration, organization, and myelination are subsequent important steps. These events and their respective timing are governed by a complex interaction of a multitude of genes. The present study applied array-based molecular karyotyping in fetuses with isolated brain malformations to search for novel causative CNVs. Based on their de novo occurrence and/or their established association with congenital brain malformations, we detected five disease-causing CNVs in four fetuses (fetus 1, fetus 10, fetus 12, and twice in Fetus 14). Furthermore, we detected a probably disease-causing $\mathrm{CNV}$ involving chromosomal region 3p26.3 in one fetus (fetus 4) and, in addition, we detected 12 CNVs in nine fetuses (fetus 2 , fetus 3 , fetus 5 , fetus 6 , fetus 7 , fetus 8 , fetus 9 , fetus 11 , and fetus 13) of unknown clinical significance. All CNVs, except for two, were absent in 1307 healthy in-house controls (frequency <0.0008). Each of the two CNVs present in in-house controls was present only once (frequency $=0.0008$ ). In the following, we will discuss the detected CNVs in the context of their associated phenotype.

\section{Dandy-Walker malformation}

Dandy-Walker malformation (DWM; OMIM $\% 220200$ ) is a heterogeneous disorder, defined by elevated tentorium and torcular, upward rotation of the vermian axis, and agenesis or partial agenesis of the cerebellar vermis with cystic dilation of the fourth ventricle, sometimes associated with secondary macrocephaly. Variable hypoplasia of cerebellar vermis with and without enlargement of the posterior fossa is named DWM variant [27, 28]. Previously, maternally transmitted CNVs (dup9p21.2, dup10p15.3) were described in two DWM patients [7], whereas FOXC1 deletions [23] and single gene mutations for FOXC1 (MIM 601090) [22], ZIC1 (MIM 600470), and ZIC4
(MIM 608948) [29] were identified in several DWM patients. Here, isolated DWM was observed in two of our fetuses (fetuses 10 and 12) and in fetus 7 with additional microcephaly and bilateral ventriculomegaly.

Fetus 7, diagnosed with DWM, carried a $1.25-\mathrm{Mb}$ duplication of chromosomal region 9p23, affecting parts of the PTPRD gene (MIM 601598) and its complete long non-coding RNA (PTPRD-AS2). PTPRD is expressed in different brain regions, acting as an important regulator of synaptic plasticity and synapse organization [30, 31]. Although duplication in 9p23 has not been reported in association with congenital brain malformation, a smaller dup9p23, affecting solely PTPRD has been detected in a patient with bipolar disorder [32]. In our fetus, the duplication of PTPRD-AS2, which may be involved in PTPRD mRNA regulation, may contribute to an unbalanced rate of protein production, thereby leading to the non-isolated DMW observed.

Fetus 10 carried a $2.43-\mathrm{Mb}$ duplication of chromosomal region $17 \mathrm{p} 11.2-17 \mathrm{p} 12$. The proximal part of this duplication has been associated with a neurobehavioral phenotype in the Potocki-Lupski syndrome [16], resulting from variable duplications at 17p11.2. Zhang et al. [33] reviewed 74 duplications involving 17 p11.2 and identified a smallest region of overlap, solely including the RAI1 (retinoic acid inducible 1) gene. The duplication detected in fetus 10 and at least in one DECIPHER patient (accession number \#274909) with microcephaly did not affect RAI1. Hence, another gene(s) might be responsible for DWM in our case. Among the 42 affected genes in our fetus is RASD1, encoding the small GTPase dexamethasone-induced Ras-related protein 1. RASD1 was shown to be a protein with enriched expression in brain, specifically coupled to neuronal nitric oxide synthase [34]. No embryonic expression data have been published; however, RASD1 has yet been localized to the suprachiasmatic nucleus, thalamus, piriform cortex, and the hippocampus in adult mice and in rat vasopressin neurons of the supraoptic nucleus and paraventricular nucleus [35, 36]. As most recently outlined by Chen and colleagues [37], RASD1 plays a central role in neuronal iron trafficking and the regulation of adenylyl cyclase and G-protein-linked neurotransmitter, making it an attractive candidate for DVM. However, it cannot be excluded that even genes outside this CNV may be affected by the duplication event.

Fetus 12 carried a $4.65-\mathrm{Mb}$ deletion involving chromosomal region 6p25.1-6p25.3 comprising FOXC1. Hence, the deletion in our fetus 12 supports the findings of Aldinger et al. [22] and Delahaye et al. [23] that FOXC1 is a major contributor to DWM and should explain the observed phenotype. In summary, 
RASD1 and PTPRD might be further contributors to the etiology of DWM.

\section{Agenesis of the corpus callosum}

Agenesis of the corpus callosum (ACC; MIM \%217990) is a clinically and genetically heterogeneous disorder [38]. Various CNVs have been observed in association with ACC $[7,10,38]$ and also mutations in several genes $[7,38]$. Here, we detected CNVs in five fetuses (fetuses $3,4,11,13$, and 14).

Fetus 3, diagnosed with ACC, carried a novel 0.51-Mb duplication affecting exon 1 of the $B C H E$ gene on 3q26.1. Soreq et al. [39] implicated this gene in cholinergic influence on cell growth and proliferation. The Mouse Gene Expression Database (http://www.informatics.jax.org/expression.shtml) reports Bche expression in the brain. Whether $B C H E$ is a candidate gene for brain malformations remains to be elucidated.

Fetus 4 carried a $0.07-\mathrm{Mb}$ deletion of chromosomal region 3p26.3, solely involving the last three exons of the CNTN6 gene. Kashevarova et al. [18] recently reported three 3p26.3 microdeletions/duplications encompassing only CNTN6 and reviewed a total of nine further cases, all presenting with ID. Also, Te Weehi et al. [40] implicated that a duplication of 3p26.3 in cognitive development and brain anomalies were always observed in the larger deletion syndrome, affecting 3p25-pter [38, 41]. Contactins are neuronal membrane proteins that mediate cell surface interactions during nervous system development. As with other family members, CNTN6 is suggested to be involved in the modulation of neurite outgrowth, synaptogenesis, survival guidance of projections, and terminal branching of axons [42]. Data from knockout mice showed Cntn6 to participate in embryonic brain development and synapse formation in postnatal cerebellar development [43]. Hence, alterations in CNTN6 dosage, caused by either deletion or duplication, may interfere with correct brain development.

Fetus 11, diagnosed with ACC, carried a $0.57-\mathrm{Mb}$ deletion of chromosomal region 16p12.2. This deletion has been extensively described by Girirajan et al. [44] and is characterized by variable clinical findings with various forms of brain anomalies, ID, or developmental delay (DD) but does not constitute a recognizable syndrome. Hence, it should explain the phenotype observed in our fetus. The region harbors seven RefSeq genes. Among the deleted genes is $C D R 2$. Cdr2 protein has been shown in human to interact with c-myc to synergistically regulate c-myc-dependent transcription during mitosis, and loss of Cdr2 leads to aberrant spindle formation and impaired proliferation [45]. Disturbance of this role for Cdr2 in dividing cells during mitosis may hence interfere with normal brain development.
Fetus 13, diagnosed with ACC, carried a maternally inherited 0.21-Mb duplication of chromosomal region at Xp22.1 comprising APOO, SAT1, and KLHL15. Several duplications of this region have been described in DECIPHER in patients with brain anomalies. Mignon-Ravix et al. [24] and most recently $\mathrm{Hu}$ et al. [46] suggested KLHL15 is a novel gene involved in X-linked ID. KLHL15 protein has been shown a substrate-specific adapter of an E3 ubiquitin-protein ligase complex, which mediates ubiquitination and subsequent proteasomal degradation of target proteins, specifically targeting protein phosphatase $2 \mathrm{~A}$, enriched in the nervous system [47]. Duplication of KLHL15 might hence release a dose-effect in this degradation process, leading to ACC.

Fetus 14, diagnosed with ACC, carried a de novo 7.2$\mathrm{Mb}$ deletion of chromosomal region Xp22.2-Xp22.32. Among the deleted genes is MID1. Mutations in MID1 have been associated with the X-linked form of Opitz syndrome [25], characterized by midline abnormalities such as cleft lip, laryngeal cleft, heart defects, hypospadias, and ACC [26]. Hence, haploinsufficiency of MID1 may explain ACC in the fetus. Besides this deletion, fetus 14 carried also a de novo 1.93-Mb duplication of chromosomal region Xp22.32-Xp22.33. Although pure duplications of this region have rarely been reported [24], several patients listed in DECIPHER showed ID, global mental delay, and even hypoplasia of the corpus callosum (patient 278363) suggesting this duplication may also contribute to the phenotype of fetus 14 .

The ACC phenotype in two of the described fetuses is most likely attributable to the deletion of MID1 and 16p12.2. Furthermore, we suggest the involvement of CNTN6 in ACC and propose $B C H E$ as a possible candidate gene for ACC.

\section{Alobar holoprosencephaly}

Holoprosencephaly (HPE) is the most common structural malformation of the human forebrain (prosencephalon), its most severe form being alobar HPE (aHPE). Here, there is only a single ventricle, no interhemispheric fissure, and the olfactory bulbs and tracts and the corpus callosum are typically absent. The etiology of HPE is extremely heterogeneous, and affected cases may have a recognizable monogenic syndrome, chromosomal anomalies, or mutations in one of the genes encoding SHH, SIX3, ZIC2, or TGIF [48].

Our analysis identified two duplications in fetus 6 , diagnosed with HPE. The first 0.25 -Mb duplication affects chromosomal region $4 \mathrm{q} 13.3$ and comprises the complete COX18 gene and part of the ANKRD17 gene. A similar duplication has been observed in three DECIPHER patients, all showing DD or ID. COX18 is required for the insertion of integral membrane proteins into the mitochondrial inner membrane and essential for the activity 
and assembly of cytochrome $\mathrm{c}$ oxidase. Data on ANKRD17 protein suggest that it interacts with proteins involved in DNA replication, as loss of $A N K R D 17$ affects Cdc6 and PCNA (proliferating cell nuclear antigen) loading onto DNA [49]. Interestingly, in a most recent report, Baple et al. [50] identified a homozygous missense mutation in the PCNA gene in four individuals from an Amish pedigree with ataxia-telangiectasia-like disorder-2 (MIM \#615919), presenting with a neurodegenerative phenotype characterized by $\mathrm{DD}$, ataxia, and sensorineural hearing loss. In vitro studies, as well as studies of patient cells, showed a negative effect of the mutation on nucleotide excision repair. These findings imply that a disturbed ANKRD17-PCNA interaction may also be involved in aHPE.

Fetus 6 also carried a 0.09-Mb duplication, including the complete $G$ protein-coupled receptor 20 (GPR20) gene at 8q24.3. GPR20 has been shown to be expressed in different brain regions [51] and seems to be involved in cellular processes like mitogenic signaling and the control of intracellular cAMP levels [52]. A role for GPR20 in aHPE is supported by several DECIPHER patients with an overlapping duplication and ACC, ID, or DD phenotypes.

\section{Isolated or non-isolated ventriculomegaly}

Ventriculomegaly is very heterogenous in nature and complex in its etiology. As outlined by Tully and Dobyns [53], it is defined as any increase in cerebrospinal fluid within the skull and more narrowly as ventricular enlargement causing accelerated head growth or requiring surgical intervention. Today, more than 10 genes have been implicated in hydrocephalus without major additional phenotypic findings, and more than 25 genes are associated with hydrocephalus and major additional physical features [53]. However, many more genes may contribute to this brain anomaly.

Here, fetus 1, diagnosed with ventriculomegaly, carried a $0.78-\mathrm{Mb}$ de novo deletion of chromosomal region 6q27. Similar deletions have frequently been observed in patients with brain anomalies including ACC, hydrocephalus, periventricular nodular heterotopia, and cerebellar malformations [15]. The smallest deleted region of overlap in these previously described patients spans $1.7 \mathrm{Mb}$, containing DLL1, C6orf70 (ERMARD), PHF10, and THBS2. Based on our findings, the newly defined smallest region of overlap excludes PHF1O and THBS2. Conti et al. [54] showed data suggesting that C6orf70, also termed ERMARD (ER membrane-associated RNA degradation), plays a major role in the control of neuronal migration, and its haploinsufficiency or mutation causes periventricular nodular heterotopia. Moreover, heterozygous ERMARD mutations have been associated with brain anomalies and periventricular nodular heterotopia 6 (OMIM \#615544) [54]. These data suggest that haploinsufficiency of ERMARD is a contributor to brain anomalies and should explain the symmetric internal hydrocephalus observed in our fetus.

Fetus 2, diagnosed with ventriculomegaly, carried a $0.10-\mathrm{Mb}$ deletion of chromosomal region 16q12.11 and a $0.39-\mathrm{Mb}$ duplication of chromosomal region 2q32.12q32.2. The deletion affects exons 2-9 of the neuropilin and tolloid (TLL)-like 2 (NETO2) gene, and overlapping deletions were reported in two DECIPHER patients (2856, 289229) who showed, among other features, ID and global DD. In rat, Neto2 was shown to be a brainspecific protein, modulating glutamate signaling in the brain by regulation of the kainate receptor function [55, 56]. Ivakine et al. [57] revealed murine Neto2 as a neuron-specific $\mathrm{K}^{+} / \mathrm{Cl}^{-}$cotransporter (Kcc2)-interacting protein required for neuronal $\mathrm{Cl}^{-}$regulation in hippocampal neurons. These findings make human NETO2 an attractive candidate gene for involvement in the etiology of hydrocephalus. The additional $0.39-\mathrm{Mb}$ duplication seen in fetus 2 involves chromosomal region 2q32.12q32.2, comprising the complete genes GULP1 and DIRC1. GULP1 is a highly evolutionarily conserved adapter protein, involved in the prompt clearance of cells undergoing apoptosis, a function critical during embryonic development, normal tissue turnover, inflammation, and autoimmunity [58]. The function of DIRC1 is yet unclear, but there is no evidence for its expression in fetal brain. As a similar duplication has not been reported thus far, it remains to be elucidated, if at least GULP1 may contribute to the phenotype observed.

Fetus 5, diagnosed with ventriculomegaly, carried a $0.18-\mathrm{Mb}$ deletion involving most of the ARHGAP10 gene on chromosome 4q31.23. A similar deletion, affecting only part of ARHGAP10 has been observed in a single DECIPHER patient (280885), who showed generalized seizures. This gene encodes a cytoskeletal Rho-GTPaseactivating protein with high levels of expression in the brain and muscle, and it is suggested to play an important role in cell differentiation [59].

Fetus 8, diagnosed with ventriculomegaly, carried a $0.19-\mathrm{Mb}$ deletion of chromosomal region 18p11.21 comprising most of the SPIRE1 gene. This region is involved in the larger $18 \mathrm{p}$ deletion syndrome, and most patients have either loss of large parts of $18 \mathrm{p}$, up to the entire $\mathrm{p}$ arm, or show a chromosomal rearrangement involving other chromosomes [60]. Monosomy 18p is often associated with brain anomalies. A correlation between the breakpoints and the mental development of seven patients led to the suggestion of a critical region between p11.1 and p11.21, since three patients with a deletion distal to this point showed normal or borderline mental development [61]. In our fetus, the deletion affected solely the SPIRE1 gene, encoding a protein involved in 
actin organization. In mice, Spire1 expression has been observed during embryogenesis in the developing nervous system and in the adult brain [62], making haploinsufficiency for SPIRE1 an attractive contributor for brain anomalies, as well as in the context of larger 18p deletions.

Fetus 9, diagnosed with ventriculomegaly, carried two duplications. The first $0.1-\mathrm{Mb}$ duplication involves chromosomal region 2q37.3, comprising KIF1A and $A Q P 12 A$. The KIF1A gene, encoding an axonal transporter of synaptic vesicles involved in nuclear migration and neurogenesis [63], has been associated with hereditary sensory and autonomic neuropathy type II and in autosomal recessive spastic paraparesis as well as spastic paraplegia [19-21]. Most recently, Okamoto et al. [64] identified a de novo heterozygous KIF1A missense mutation in a patient with progressive neurodegeneration. A similar CNV as that observed in our fetus has also been deposited in DECIPHER (patient 2692) affected with ID and small stature.

The second $0.08-\mathrm{Mb}$ duplication involved chromosomal region 3q13.32 and comprised the IGSF11 gene. IGSF11 is an immunoglobulin (Ig) superfamily member, preferentially expressed in the brain and testis [65]; however, an involvement in the etiology of brain malformations has not been reported and a similar duplication has not been observed yet. According to our observation and previous reports, we suggest, at minimum, KIF1A as a possible disease-causing gene in brain plasticity and suggest a causal relationship with the fetal phenotype.

While we were able to identify disease-causing and probably disease-causing CNVs, our study has several limitations, inherent to its design: The fetal brain develops dynamically and depending on the gestational age, a given developmental stage may not yet have taken place. Accordingly, certain malformations manifest themselves late in gestation or postnatally, e.g., some neuronal migration disorders and septo-optic dysplasia, which are often combined with agenesis of the corpus callosum, will only be detectable by imaging techniques late in pregnancy or even postnatally. Additionally, at the time of recruitment, cerebral magnetic resonance tomography was not yet established as an adjunct for the diagnosis of fetal brain malformations. Finally, the results of neurohistologic examinations are limited due to the autolytic process occurring between fetocide and delivery.

\section{Conclusions}

Our $\mathrm{CNV}$ analysis revealed disease-causing CNVs in $12 \%$ (four out of 33 fetuses) involving chromosomal regions 6p25.1-6p25.3, 6q27, 16p12.3, Xp22.2-Xp22.32, and $\mathrm{Xp} 22.32-\mathrm{Xp} 22.33$. Furthermore, we detected a probably disease-causing $\mathrm{CNV}$ involving chromosomal region 3p26.3 and additional 12 rare CNVs (frequency $\leq 0.0008$ ) in nine fetuses of unknown clinical significance. Our study suggests that CNVs play an important role in the etiology of isolated brain malformations.

\section{Competing interests}

The authors declare that they have no competing interests.

\section{Authors' contributions \\ ML, WMM, and HR conceived and designed the experiments. UG and WMM collected all the fetal samples and diagnoses. MS, AH, SKK, AH, FM, and DS performed the experiments and analyzed the data. MS, ML, and HR wrote the manuscript. All authors discussed the results and interpretations, contributed to manuscript preparation, and read and approved the final version.}

\section{Acknowledgements}

S.K. is supported by the BONFOR program of the University of Bonn (grant number O-149.0101). This study made use of data generated by the Decipher Consortium (http://decipher.sanger.ac.uk/).

\section{Author details}

${ }^{1}$ Institute of Human Genetics, University of Bonn, Bonn, Germany. ${ }^{2}$ Department of Genomics, Life and Brain Center, University of Bonn, Bonn, Germany. ${ }^{3}$ Department of Obstetrics and Prenatal Medicine, University of Bonn Medical School, Bonn, Germany. ${ }^{4}$ Department of Clinical Chemistry and Clinical Pharmacology, University of Bonn, Bonn, Germany. ${ }^{5}$ Department of Neonatology and Pediatric Intensive Care \& Institute of Human Genetics, University of Bonn, Sigmund-Freud-Str. 25, D-53127 Bonn, Germany.

Received: 2 November 2015 Accepted: 15 March 2016

Published online: 15 April 2016

\section{References}

1. McGahan JP, Pilu G, Nyberg DA. Cerebral malformations. In: Nyberg DA McGahan JP, Pretorius DH, Pilu G, editors. Diagnostic imaging of fetal anomalies. Philadelphia: Lippincott Williams \& Wilkins; 2003. p. 221-91.

2. Chitty LS, Pilu G. The challenge of imaging the fetal central nervous system: an aid to prenatal diagnosis, management and prognosis. Prenat Diagn. 2009;29:301-2.

3. Verity $\mathrm{C}$, Firth $\mathrm{H}$, ffrench-Constant $\mathrm{C}$. Congenital abnormalities of the central nervous system. J Neurol Neurosurg Psychiatry. 2003;74 Suppl 1:i3-8.

4. Girard NJ. Cerebral malformations without antenatal diagnosis. Pediatr Radiol. 2010;40:834-43.

5. Anonymous. Prevention of neural tube defects: results of the Medical Research Council Vitamin Study. MRC Vitamin Study Research Group. Lancet. 1991;338:131-7.

6. Jeng LB, Tarvin R, Robin NH. Genetic advances in central nervous system malformations in the fetus and neonate. Semin Pediatr Neurol. 2001:8:89-99.

7. Kariminejad R, Lind-Thomsen A, Tümer Z, Erdogan F, Ropers H, Tommerup $\mathrm{N}$, et al. High frequency of rare copy number variants affecting functionally related genes in patients with structural brain malformations. Hum Mutat. 2011;32:1427-35.

8. Wapner RJ, Martin CL, Levy B, Ballif BC, Eng CM, Zachary JM, et al. Chromosomal microarray versus karyotyping for prenatal diagnosis. N Engl J Med. 2012;367:2175-84.

9. Hillman SC, McMullan DJ, Silcock L, Maher ER, Kilby MD. How does altering the resolution of chromosomal microarray analysis in the prenatal setting affect the rates of pathological and uncertain findings? J Matern Fetal Neonatal Med. 2014;27:649-57.

10. Sajan SA, Fernandez L, Nieh SE, Rider E, Bukshpun P, Wakahiro M, et al. Both rare and de novo copy number variants are prevalent in agenesis of the corpus callosum but not in cerebellar hypoplasia or polymicrogyria. PLoS Genet. 2013;9:e1003823.

11. De Wit MC, Srebniak MI, Govaerts LC, van Opstal D, Galjaard RJ, Go AT. Additional value of prenatal genomic array testing in fetuses with isolated structural ultrasound abnormalities and a normal karyotype: a systematic review of the literature. Ultrasound Obstet Gynecol. 2014;43:139-46. 
12. Krutzke SK, Engels H, Hofmann A, Schumann MM, Cremer K, Zink AM, et al. Array-based molecular karyotyping in fetal brain malformations: identification of novel candidate genes and chromosomal regions. Birth Defects Res A Clin Mol Teratol. 2015;106:16-26.

13. Colella S, Yau C, Taylor JM, Mirza G, Butler H, Clouston P, et al. An objective Bayes hidden-Markov model to detect and accurately map copy number variation using SNP genotyping data. Nucleic Acids Res. 2007;35:2013-25.

14. Draaken M, Giesen CA, Kesselheim AL, Jabs R, Aretz S, Kugaudo M, et al. Maternal de novo triple mosaicism for two single OCRL nucleotide substitutions (c.1736A > T, c.1736A > G) in a Lowe syndrome family. Hum Genet. 2011;129:513-9.

15. Peddibhotla S, Nagamani SC, Erez A, Hunter JV, Holder Jr JL, Carlin ME, et al. Delineation of candidate genes responsible for structural brain abnormalities in patients with terminal deletions of chromosome $6 q 27$. Eur J Hum Genet. 2015;23:54-60.

16. Potocki L, Bi W, Treadwell-Deering D, Carvalho CM, Eifert A, Friedman EM, et al. Characterization of Potocki-Lupski syndrome (dup(17) (p11.2p11.2)) and delineation of a dosage-sensitive critical interval that can convey an autism phenotype. Am J Hum Genet. 2007;80:633-49.

17. Hu J, Liao J, Sathanoori M, Kochmar S, Sebastian J, Yatsenko SA, et al. CNTN6 copy number variations in 14 patients: a possible candidate gene for neurodevelopmental and neuropsychiatric disorders. J Neurodev Disord. 2015;7:26.

18. Kashevarova AA, Nazarenko LP, Schultz-Pedersen S, Skryabin NA, Salyukova $\mathrm{OA}$, Chechetkina NN, et al. Single gene microdeletions and microduplication of 3p26.3 in three unrelated families: CNTN6 as a new candidate gene for intellectual disability. Mol Cytogenet. 2014;7:97.

19. Klebe S, Azzedine H, Durr A, Bastien P, Bouslam N, Elleuch N, et al. Autosomal recessive spastic paraplegia (SPG30) with mild ataxia and sensory neuropathy maps to chromosome 2q37.3. Brain. 2006;129:1456-62.

20. Erlich Y, Edvardson S, Hodges E, Zenvirt S, Thekkat P, Shaag A, et al. Exome sequencing and disease-network analysis of a single family implicate a mutation in KIF1A in hereditary spastic paraparesis. Genome Res. 2011;21:658-64.

21. Rivière JB, Ramalingam S, Lavastre $V$, Shekarabi M, Holbert $S$, Lafontaine J, et al. KIF1A, an axonal transporter of synaptic vesicles, is mutated in hereditary sensory and autonomic neuropathy type 2. Am J Hum Genet. 2011;89:21930 .

22. Aldinger KA, Lehmann OJ, Hudgins L, Chizhikov W, Bassuk AG, Ades LC, et al. FOXC1 is required for normal cerebellar development and is a major contributor to chromosome 6p25.3 Dandy-Walker malformation. Nat Genet. 2009:41:1037-42.

23. Delahaye A, Khung-Savatovsky S, Aboura A, Guimot F, Drunat S, Alessandri $J$, et al. Pre- and postnatal phenotype of 6 p25 deletions involving the FOXC1 gene. Am J Med Genet A. 2012;158A:2430-8.

24. Mignon-Ravix C, Cacciagli P, Choucair N, Popovici C, Missirian C, Milh M, et al. Intragenic rearrangements in $\mathrm{X}$-linked intellectual deficiency: results of a-CGH in a series of 54 patients and identification of TRPC 5 and KLHL15 as potential XLID genes. Am J Med Genet A. 2014;164A:1991-7.

25. Quaderi NA, Schweiger S, Gaudenz K, Franco B, Rugarli El, Berger W, et al. Opitz G/BBB syndrome, a defect of midline development, is due to mutations in a new RING finger gene on Xp22. Nat Genet. 1997;17:285-91.

26. Robin NH, Feldman GJ, Aronson AL, Mitchell HF, Weksberg R, Leonard CO, et al. Opitz syndrome is genetically heterogeneous, with one locus on Xp22, and a second locus on 22q11.2. Nat Genet. 1995;11:459-61.

27. Malinger G, Lev D, Lerman-Sagie T. The fetal cerebellum. Pitfalls in diagnosis and management. Prenat Diagn. 2009;29:372-80.

28. Garel C, Fallet-Bianco C, Guibaud L. The fetal cerebellum: development and common malformations. J Child Neurol. 2011;26:1483-92.

29. Grinberg I, Northrup H, Ardinger H, Prasad C, Dobyns WB, Millen KJ. Heterozygous deletion of the linked genes ZIC 1 and ZIC4 is involved in Dandy-Walker malformation. Nat Genet. 2004;36:1053-5.

30. Uetani N, Kato K, Ogura H, Mizuno K, Kawano K, Mikoshiba K, et al. Impaired learning with enhanced hippocampal long-term potentiation in PTPSdeficient mice. EMBO J. 2000;19:2775-85.

31. Takahashi H, Craig AM. Protein tyrosine phosphatases PTPS, PTP $\sigma$, and LAR: presynaptic hubs for synapse organization. Trends Neurosci. 2013;36:522-34.

32. Malhotra D, McCarthy S, Michaelson JJ, Vacic V, Burdick KE, Yoon S, et al. High frequencies of de novo CNVs in bipolar disorder and schizophrenia. Neuron. 2011;72:951-63.

33. Zhang F, Potocki L, Sampson JB, Liu P, Sanchez-Valle A, Robbins-Furman P, et al. Identification of uncommon recurrent Potocki-Lupski syndrome- associated duplications and the distribution of rearrangement types and mechanisms in PTLS. Am J Hum Genet. 2010;86:462-70.

34. Fang M, Jaffrey SR, Sawa A, Ye K, Luo X, Snyder SH. Dexras1: a G protein specifically coupled to neuronal nitric oxide synthase via CAPON. Neuron. 2000;26:183-93.

35. Takahashi H, Umeda N, Tsutsumi $Y$, Fukumura R, Ohkaze $H$, Sujino $M$, et al. Mouse dexamethasone-induced RAS protein 1 gene is expressed in a circadian rhythmic manner in the suprachiasmatic nucleus. Mol Brain Res. 2003;110:1-6.

36. Greenwood MP, Greenwood M, Mecawi AS, Antunes-Rodrigues J, Paton JFR, Murphy D. Rasd1, a small G protein with a big role in the hypothalamic response to neuronal activation. Mol Brain. 2016;9:1.

37. Chen Y, Mathias L, Falero-Perez JM, Kim SF. PKA-mediated phosphorylation of Dexras1 suppresses iron trafficking by inhibiting S-nitrosylation. FEBS Lett. 2015;589:3212-9.

38. Schell-Apacik CC, Wagner K, Bihler M, Ertl-Wagner B, Heinrich U, Klopocki E, et al. Agenesis and dysgenesis of the corpus callosum: clinical, genetic and neuroimaging findings in a series of 41 patients. Am J Med Genet A. 2008; 146A:2501-11.

39. Soreq H, Ehrlich G, Schwarz M, Loewenstein Y, Glick D, Zakut H. Mutations and impaired expression in the ACHE and BCHE genes: neurological implications. Biomed Pharmacother. 1994;48:253-9.

40. Te Weehi L, Maikoo R, Mc Cormack A, Mazzaschi R, Ashton F, Zhang L, et al. Microduplication of 3p26.3 implicated in cognitive development. Case Rep Genet. 2014;2014:295359.

41. Mowrey PN, Chorney MJ, Venditti CP, Latif F, Modi WS, Lerman MI, et al. Clinical and molecular analyses of deletion 3p25-pter syndrome. Am J Med Genet. 1993:46:623-9.

42. Zuko A, Kleijer KT, Oguro-Ando A, Kas MJ, van Daalen E, van der Zwaag B, et al. Contactins in the neurobiology of autism. Eur J Pharmacol. 2013;719: 63-74.

43. Sakurai K, Toyoshima M, Ueda H, Matsubara K, Takeda Y, Karagogeos D, et al. Contribution of the neural cell recognition molecule NB-3 to synapse formation between parallel fibers and Purkinje cells in mouse. Dev Neurobiol. 2009;69:811-24.

44. Girirajan S, Moeschler J, Rosenfeld J. 16p12.2 microdeletion. In: Pagon RA, Adam MP, Ardinger HH, Wallace SE, Amemiya A, Bean LJH, Bird TD, Dolan CR, Fong CT, Smith RJH, Stephens K, editors. GeneReviews ${ }^{\oplus}$ [Internet]. Seattle: University of Washington; 2015. p. 1993-2015.

45. O'Donovan KJ, Diedler J, Couture GC, Fak JJ, Darnell RB. The onconeural antigen cdr2 is a novel APC/C target that acts in mitosis to regulate c-myc target genes in mammalian tumor cells. PLoS One. 2010;5:e10045.

46. Hu H, Haas SA, Chelly J, Van Esch H, Raynaud M, de Brouwer AP, et al. $X$-exome sequencing of 405 unresolved families identifies seven novel intellectual disability genes. Mol Psychiatry. 2015;(in press) doi: 10.1038/mp. 2014.193.

47. Oberg EA, Nifoussi SK, Gingras AC, Strack S. Selective proteasomal degradation of the $B^{\prime} \beta$ subunit of protein phosphatase $2 A$ by the E3 ubiquitin ligase adaptor Kelch-like 15. J Biol Chem. 2012;287:43378-89.

48. Raam MS, Solomon BD, Muenke M. Holoprosencephaly: a guide to diagnosis and clinical management. Indian Pediatr. 2011;48:457-66.

49. Deng M, Li F, Ballif BA, Li S, Chen X, Guo L, et al. Identification and functional analysis of a novel cyclin e/cdk2 substrate ankrd17. J Biol Chem. 2009;284:7875-88.

50. Baple EL, Chambers H, Cross HE, Fawcett H, Nakazawa Y, Chioza BA, et al. Hypomorphic PCNA mutation underlies a human DNA repair disorder. J Clin Invest. 2014;124:3137-46.

51. O'Dowd BF, Nguyen T, Jung BP, Marchese A, Cheng R, Heng HH, et al. Cloning and chromosomal mapping of four putative novel human G-protein-coupled receptor genes. Gene. 1997;187:75-81.

52. Hase M, Yokomizo T, Shimizu T, Nakamura M. Characterization of an orphan G protein-coupled receptor, GPR20, that constitutively activates Gi proteins. J Biol Chem. 2008;283:12747-55.

53. Tully HM, Dobyns WB. Infantile hydrocephalus: a review of epidemiology, classification and causes. Eur J Med Genet. 2014;57:359-68.

54. Conti V, Carabalona A, Pallesi-Pocachard E, Parrini E, Leventer RJ, Buhler E, et al. Periventricular heterotopia in $6 \mathrm{q}$ terminal deletion syndrome: role of the C6orf70 gene. Brain. 2013;136:3378-94.

55. Zhang W, St-Gelais F, Grabner CP, Trinidad JC, Sumioka A, Morimoto-Tomita $M$, et al. A transmembrane accessory subunit that modulates kainate-type glutamate receptors. Neuron. 2009;61:385-96. 
56. Copits BA, Robbins JS, Frausto S, Swanson GT. Synaptic targeting and functional modulation of GluK1 kainate receptors by the auxiliary neuropilin and tolloid-like (NETO) proteins. J Neurosci. 2011;31:7334-40.

57. Ivakine EA, Acton BA, Mahadevan V, Ormond J, Tang M, Pressey JC, et al. Neto2 is a KCC2 interacting protein required for neuronal Cl-regulation in hippocampal neurons. Proc Natl Acad Sci U S A. 2013;110:3561-6.

58. Su HP, Nakada-Tsukui K, Tosello-Trampont AC, Li Y, Bu G, Henson PM, et al. Interaction of CED-6/GULP, an adapter protein involved in engulfment of apoptotic cells with CED-1 and CD91/low density lipoprotein receptorrelated protein (LRP). J Biol Chem. 2002;277:11772-9.

59. Bassères DS, Tizzei EV, Duarte AA, Costa FF, Saad ST. ARHGAP10, a novel human gene coding for a potentially cytoskeletal Rho-GTPase activating protein. Biochem Biophys Res Commun. 2002;294:579-85.

60. Turleau C. Monosomy 18p. Orphanet J Rare Dis. 2008;3:4.

61. Wester U, Bondeson ML, Edeby C, Annerén G. Clinical and molecular characterization of individuals with $18 p$ deletion: a genotype-phenotype correlation. Am J Med Genet A. 2006;140A:1164-71.

62. Schumacher N, Borawski JM, Leberfinger CB, Gessler M, Kerkhoff E. Overlapping expression pattern of the actin organizers Spir-1 and formin-2 in the developing mouse nervous system and the adult brain. Gene Expr Patterns. 2004;4:249-55.

63. Tsai JW, Lian WN, Kemal S, Kriegstein AR, Vallee RB. Kinesin 3 and cytoplasmic dynein mediate interkinetic nuclear migration in neural stem cells. Nat Neurosci. 2010;13:1463-71.

64. Okamoto N, Miya F, Tsunoda T, Yanagihara K, Kato M, Saitoh S, et al. KIF1A mutation in a patient with progressive neurodegeneration. J Hum Genet. 2014;59:639-41.

65. Suzu S, Hayashi Y, Harumi T, Nomaguchi K, Yamada M, Hayasawa H, et al. Molecular cloning of a novel immunoglobulin superfamily gene preferentially expressed in brain and testis. Biochem Biophys Res Commun. 2002;296:1215-21.

\section{Submit your next manuscript to BioMed Central and we will help you at every step:}

- We accept pre-submission inquiries

- Our selector tool helps you to find the most relevant journal

- We provide round the clock customer support

- Convenient online submission

- Thorough peer review

- Inclusion in PubMed and all major indexing services

- Maximum visibility for your research

Submit your manuscript at www.biomedcentral.com/submit
Biomed Central 